\title{
ІТ-ТЕХНОЛОГИИ В УЧЕТНО-АНАЛИТИЧЕСКОМ ОБЕСПЕЧЕНИИ В ЦЕЛЯХ УПРАВЛЕНИЯ ОРГАНИЗАЦИЕЙ
}

\section{(c) 2019 Андреева Светлана Юрьевна}

кандидат экономических наук, доцент Кафедры финансов экономики и организации производства Поволжский государственный технологический университет, Россия, Респ. Марий Эл, Йошкар-Ола

E-mail:buh@tk12region.ru

\section{(c) 2019 Шлычков Дмитрий Сергеевич}

кандидат экономических наук, доцент Департамента учета, анализа и аудита

Финансовый университет при Правительстве Российской Федерации, Россия, Москва

E-mail: sds457@mail.ru

В условиях мировой цифровизации объектов систем управления организацией возникает потребность в более детальной проработанности IT-технологий в учетно-аналитической деятельности хозяйствующего субъекта. Развитие информационных систем обработки информации на уровне экономического субъекта послужило предметом исследования.

В процессе исследования вопроса IT-технологий в учетно-аналитическом обеспечении применялись методы: наблюдение и сбор фактов, системный подход, индукция и дедукция, исторический и логический.

Управление информационным потоком в организации требует стратегического подхода, который позволяет системно выстроить информацию для принятия управленческих решений в учетно-аналитическом и управленческом менеджменте. Стратегический подход охватывает большую область управления организацией начиная с миссии и заканчивая анализом хозяйственных процессов. Основным результатом исследования является анализ внедрения IT-технологий в систему учетно-аналитического обеспечения в целях управления организацией, их содержание от формирования концептуальной схемы построения до внедрения бюджетного управления как одного из методов контроллинга (ERP-система, SAP, SWOT-анализ и другие). В настоящее время использование этих систем является необходимостью в управленческой деятельности организации.

Инновационные подходы к управлению организацией определяют ее конкурентоспособность на внешних в внутренних рынках. Реализация стратегических подходов позволяет оперативно реагировать на изменения в экономике страны и мира, что способствует эффективной работе по реализации товаров (работ, услуг) на рынках сбыта.

Ключевые слова: стратегическое управление, ERP-система, учетно-аналитическое обеспечение, планирование, прогнозирование.

Современная экономическая модель страны предъявляет жесткие требования для эффективного и стабильного функционирования организаций на рынке. Основным подходом является стратегия на среднесрочную и долгосрочную перспективы в целях учетно-аналитического обеспечения устойчивого развития. В этой связи от организации требуется регулярный менеджмент бизнес-процессов учетно-аналитической информации как внешней (экономическая и политическая обстановка в стране, отношение стран партнеров через предъявляемые санкции, другие факторы), так и внутренней (классическая модель «снабжение-производства-сбыт») с целью прогнозирования рисков деятельности организации.
Регулярный менеджмент - это постоянное применение в практике управления организацией регламентированных процедур выработки, принятия и реализации учетно-аналитических решений. Он позволяет бороться со стихийным «стечением обстоятельств», противостоять агрессивным изменениям внешней среды, добиваться поставленных перед организацией целей.

Принятие организационных решений требует обеспечения менеджеров точной и своевременной информацией. Поэтому регулярный менеджмент невозможен без регулярного бухгалтерского (управленческого) учета, призванного обеспечить такой учетно-аналитической информацией лиц, принимающих решения.

Организация как объект является сложной 
структурой, в которой персонал является основным звеном, требующим управления через согласованность, регламентированость и направленность, а персонал в свою очередь имеет свои интересы, трансформирующиеся в интересы групп и организации в целом. Следовательно, регулярный менеджмент, опирающийся на регулярные процедуры, требует проектирования этих процедур. Система учета, система управления, организационная структура, внутренние регламенты требуют проектирования и внедрения этих проектов.

Понятийная или концептуальная схема это совокупность понятий и отношений между ними. Она задает минимальный объем терминов и закрепленного за ними содержания, который необходим для того, чтобы точно поставить задачу, сформулировать проблему, описать ее решение.

Для того чтобы описать требования к организации, построить проект структуры управления организации, задать ее функциональную или организационную структуру, необходимо иметь соответствующие понятия, которые содержаться в разнообразных концептуальных схемах, только понятия эти иные - процесс, функция, поддержание, управление.

Модель - это концептуальная схема, понятиям которой сопоставлены конкретные объекты, явления, процессы из той предметной об- ласти, которую описывает схема. Такой процесс сопоставления называется интерпретацией, и модель, таким образом, есть интерпретированная концептуальная схема.

Концептуальная схема учетно-аналитического обеспечения организации может основываться на: организационной структуре предприятия, сети бизнес-процессов (рис. 1).

Организационная структура компании - это модель этой компании, основанная на концептуальных схемах организационных, функциональных и властных отношений. В концептуальной схеме организационных отношений введены такие понятия, как подразделение, организация, организационная вертикаль. Другой моделью организации может быть модель центров ответственности. Она используется для проектирования системы контроллинга. Модель центров финансовой ответственности лежит в основе построения процедур планирования. Модель бизнес-процессов применяется для регламентации материальных потоков и документооборота и т.д.

Подход, основанный на проектировании процедур управления и учета с применением моделей организации (нормативный подход), не является новым. Реинжениринг бизнес-процессов целиком основан на построении модели организации как сети процессов. Системный анализ в его классическом виде предлагает ме-

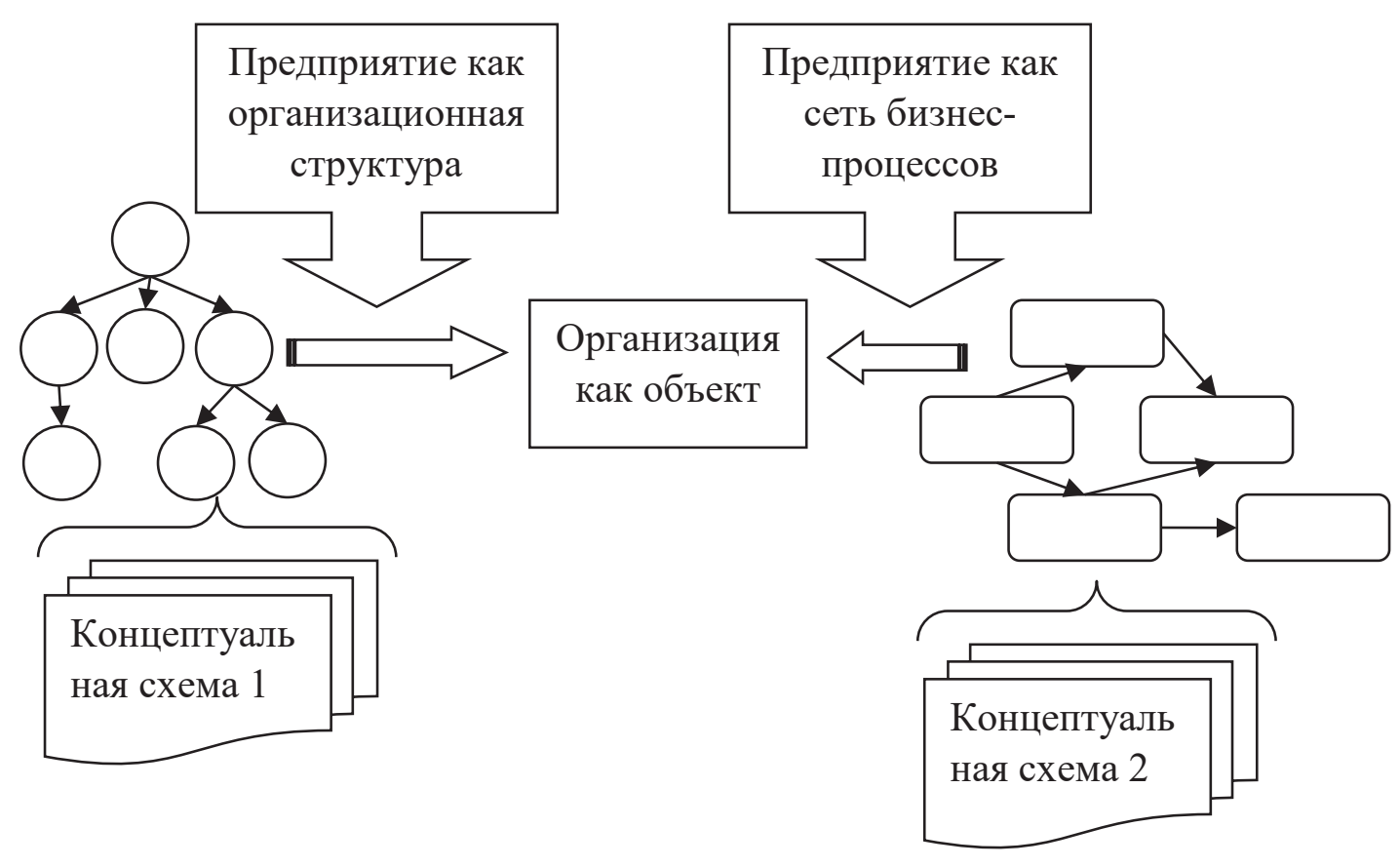

Рис. 1. Подходы к концептуальной схеме учетно-аналитического обеспечения организации 
тод решения проблем бизнеса на основе применения модели целенаправленной системы, которая задает полную номенклатуру функций управления.

Большое влияние на устойчивое развитие предприятия оказывает уровень информатизации, возможность оперировать информацией оперативно и своевременно принимать решения на всех уровнях управления.

Предпочтение из всевозможных автоматизированных систем управления отдается системам, включающим в себя управление по стандарту ERP.

«Сохраняется высокий спрос на ERP-консалтинг. Наибольшей популярностью данная услуга пользуется у крупных машиностроительных предприятий.

Ещё одна устойчивая тенденция - рост спроса на отраслевые ERP, учитывающие специфику бизнес-процессов, стандарты и особенности регулирования конкретных индустрий. Плюс к этому, организации всех отраслей от «лоскутной автоматизации» постепенно переходят к комплексным решениям на единой программной платформе (типа 1C).

Ключевые направления развития самих ERP-систем:

1. Упрощение пользовательских интерфейсов. Поскольку ERP-системы всё активнее используются на мобильных устройствах, они должны иметь интуитивно-понятный интерфейс. Кроме того, они должны быть оснащены функционалом, повышающим удобство пользования: умным ассистентом, предиктивным вводом, адаптивным дизайном.

2. Включение интеллектуальных функций. Для того чтобы идти в ногу со временем, разработчикам ERP-систем уже сейчас следует позаботиться о развитии функционала прогнозирования и анализа. Применение технологий искусственного интеллекта (нейронных сетей, машинного обучения и т.д.) позволит клиентским предприятиям прогнозировать потребности, оптимизировать технологические процессы, предотвращать хищения, выявлять нарушения технологических процессов, предлагать оптимизацию технологических и бизнес-процессов» [15].

Глава Минкомсвязи Николай Никифоров выступил на конференции TAdviser IT Government 2018 и ответил на актуальные вопросы о построении цифровой экономики в России. По заяв- лению министра, за цифровизацию экономики отвечает не какое-то отдельно взятое ведомство, а все участники профессионального ИТ-сообщества вместе. Николай Анатольевич призвал игроков рынка к активному сотрудничеству с органами, регулирующими и контролирующими реализацию программы цифровой экономики. «Программа не администрируется никаким отдельно взятым министерством, и даже аппарат Правительства РФ играет лишь «подруливающую» роль. Вся инициатива находится в руках ИТ-индустрии: центров компетенции, экспертных групп, в работе которых участвуют сотни специалистов, делегированных ИТ-компаниями».

Программа «Цифровая экономика» главная задача которой - экономический рост, дополнительные конкурентные преимущества для нашей страны на международном рынке, и в этом контексте решаемые нами технологические задачи - лишь кирпичики для роста экономики. Это понимают и политики, и бизнес, поскольку даже бизнес сегодня все больше конкурирует на глобальном рынке, а не внутри. Мы добываем руду, перерабатываем ее в металл, делаем продукцию машиностроения, экспортируем. И то же относится к другим отраслям - финансовой, здравоохранению, образованию. Мы никогда не сможем поднять уровень жизни граждан, если не будем конкурентоспособны на глобальном уровне. А это невозможно без внедрения цифровых технологий.

«ERP-система - система планирования и управления ресурсами предприятия (Enterprise Resource Planning - Планирование ресурсов предприятия), призванная оптимизировать все внутренние и внешние бизнес-процессы. ERP-системы позволяют снизить операционные, управленческие и коммерческие затраты, сократить цикл реализации, увеличить оборачиваемость материальных запасов, улучшить утилизацию основных фондов и т.д.» [4].

В практике применения IT-технологий в области учетно-аналитического обеспечения организации сложились уровневые подходы к применению автоматизированных систем по уровню менеджмента организации (рис. 2).

Ведение бухгалтерского учета - это важная задача для любой компании. ERP-системы должны помочь решать эту задачу.

На практике очень часто приходится сталкиваться с жалобами пользователей, которые то и 

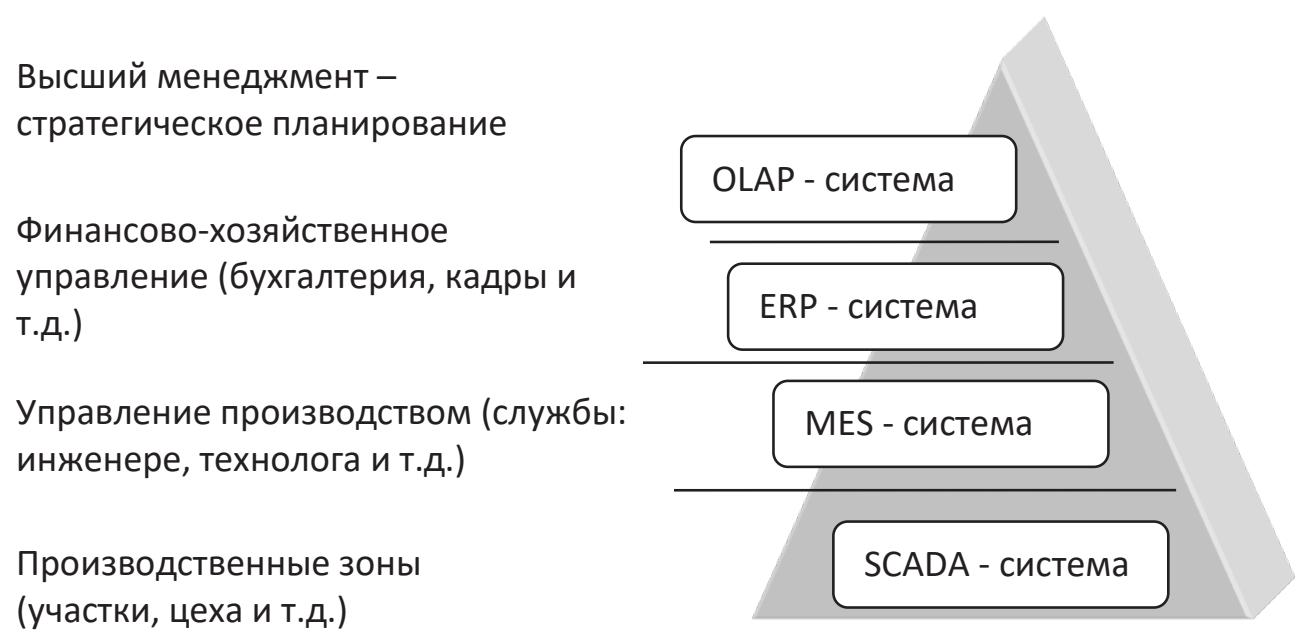

Puc. 2. Автоматизированные системы организации

дело указывают на некомпетентность системы, ее неприспособленность к бухгалтерским реалиям.

Непривычный вид зарегистрированных в системе бухгалтерских записей часто вызывает затруднение у пользователей: одна запись отображается двумя строками.

Однако важно понимать, что любая учетная система ведет бухгалтерский учет в соответствии с правилом двойной записи и обе строки являются соответствующими дебетом и кредитом одной записи.

Большая часть организаций в России привыкла использовать корреспондирующие бухгалтерские записи, которые выглядят как одна строка: дебет слева, кредит справа и сумма.

Современные ERP-системы не призывают отказываться от этой привычки, в локализованных для России версиях есть возможность включить использование корреспонденции. Следует отметить, что многие компании, особенно это касается тех, которые предоставляют отчетность в МСФО, ведут учет без корреспонденции.

Невозможно изменить и удалить учтенные документы. Удалить или изменить бухгалтерские записи Главной книги, отгрузочные документы и другие учтенные данные нельзя.

Часто это вызывает острую критику системы со стороны пользователя, подкрепленную боязнью совершить ошибку, которую нельзя исправить. Такую же реакцию часто вызывает невозможность проведения документов задним числом.

Однако категоричное «нельзя изменить, ис- править» не точно отражает логику ERP, соответствующую международным стандартам.

Любые данные можно откорректировать - аннулировать ошибочные, ввести новые правильные и снова провести их учет. Главным отличием от простой замены данных является наглядность истории изменений: одно дело - просто заменить значение цены «10,00» на «100,00» и затем долго искать причину расхождений, а совсем другое дело - записать процесс замены «10,00» на «100,00» и ясно увидеть причину расхождений. В результате вы получаете гарантию целостности данных и достоверные отчеты, отражающие реальное текущее состояние дел.

Главная книга - это основа ERP-системы пользователя-бухгалтера.

Этот факт порождает две реакции: страх за целостность и корректность данных со стороны бухгалтера, когда он представляет, как сотрудник склада пытается сформировать какую-нибудь запись в главной книге, и страх сотрудника склада, когда он представляет масштаб и ответственность предстоящего события.

Однако эти действия сотрудников совершенно не обоснованы и не подкрепляются логикой процессов, протекающих в системе. Сотрудник склада будет работать в складском модуле ERP-системы, записи в котором отображают реальное движение ТМЦ: приходы, расходы и перемещения по складам, и наименования бухгалтерских счетов для него не играют никакого значения. Бухгалтер, в свою очередь, будет иметь дело с бухгалтерскими записями по сче- 
там в Главной книге в соответствии с преднастроенными правилами разноски. Связь между модулями позволяет проследить происхождение любой проводки, которую видит бухгалтер.

Важно также отметить, что любая зарубежная ERP-система адаптирована под российские реалии.

У многих организаций существует потребность ведения бухгалтерского учета в двух стандартах - РСБУ и МСФО (или любом формате получения управленческой отчетности). Часто пользователям кажется, что в решении этой задачи ERP-система накладывает на них дополнительные обязательства, увеличивая вдвое объем работы. Но что представляет собой каждый из видов учета? Это отображение одних и тех же фактов хозяйственной деятельности организации в разных разрезах. А значит, встает вопрос лишь в правильной регистрации данных в ERP-системе таким образом, чтобы они удовлетворяли потребностям разных видов учета.

Исследователи Panorama Consulting Solutions попытались разобраться, почему так происходит. Исходя из собственного 10-летнего опыта внедрения ERP и примеров успешного преодоления проблем другими организациями, компания пришла к выводу, что всё зависит с выработки стратегического подхода в самом начале проекта. Вот 5 драйверов успешного внедрения ERP:

1) Чёткая согласованность с общей бизнес-стратегией компании. Несоответствие целей внедрения ERP общей стратегии развития компании - одна из самых труднопреодолимых проблем реализации проекта. Не так давно Panorama сама работала с организацией, проводящей цифровую трансформацию бизнеса в надежде обойти конкурентов. Основной целью внедрения новых технологий для неё было улучшение качества обслуживания клиентов. Однако внедрение ERP было больше ориентировано на оптимизацию и автоматизацию функций бэк-офиса (операционно-учётного подразделения), а не на совершенствование клиентского сервиса. Данная несогласованность привела к путанице, повышению расходов по проекту и размытию результатов, не оправдавших ожидания ни клиентов, ни исполнителей.

2) Реалистичность ожиданий на этапе планирования. По замечанию исследователей, многие ERP-проекты обречены с самого начала. Изза нереалистичных ожиданий команды проекта. K примеру, если вы поручите своей управлен- ческой команде завершить проект в нереально короткие сроки или уложиться в минимальный бюджет, это приведёт к сжатию важнейших проектных операций (таких, как управление организационными изменениями и оптимизация бизнес-процессов). Всё это, по иронии, вызывает обратный эффект - перерасход времени и бюджета.

3) Упор на управление организационными изменениями и адаптацию персонала. Согласно результатам исследования «ЕRP-2018», основной причиной увеличения бюджетов и сроков внедрения являются организационные проблемы и неготовность кадров к переменам. Но это решаемо. Надо только всех противников внедрения превратить в заинтересованных союзников. Объясните, какие преимущества получит бизнес, как повысится ROI, на сколько увеличится прибыль. Успешные примеры внедрений свидетельствуют, что инвестиции в управление организационными изменениями снижают общую стоимость и риски внедрения.

4) Эффективное управление и оптимизация бизнес-процессов. Само по себе внедрение ERP не меняет бизнес-процессов. Их надо отлаживать заранее - до момента развёртывания программного обеспечения. Современные ERP-системы предельно гибки и понятны, легко подстраиваются под любые сценарии, так что адаптировать под них существующие бизнес-процессы не придётся.

5) Сильная команда управления и контроля. В «Уставе» проекта должны быть чётко прописаны структура управления и контроля, роли и зоны ответственности всех участников команды. Управление должно соответствовать уникальным потребностям и динамике организации. Управление должно быть одновременно всеобъемлющим и динамичным, специфичным и воспроизводимым. Из технологической инициативы внедрение ERP может превратиться в комплексную бизнес-трансформацию. Поэтому в самом начале проекта важно собрать надёжную команду управления и контроля.

Цифровые технологии - это факт современности и ежедневные реалии для каждого предприятия и руководителя. Скорость проникновения цифровой реальности в практику ведения бухгалтерского и налогового учета часто выше, чем внедрение технологий на производственных площадках

Частота обновления законодательных тре- 
бований, несоответствие новых изменений не отмененным старым стандартам требуют от бухгалтера глубокой юридической экспертизы, налаженных связей с профессиональными консультантами и умение аргументировать свою позицию со ссылкой на точную норму Закона.

Цифровые технологии предлагают современные методы автоматизации простых участков ведения учета, а это значит, что в учебной программе должно появиться время на изучение прикладных учетных систем или программных комплексов. Современный бухгалтер - это уже не тот сотрудник, который работает с одной программой бухгалтерского учета (пусть пока и самой распространенной) еще со времен учебы в ВУЗЕ в течение десятков лет.

Он создает бизнес-процессы и ставит задачи разработчикам согласно финансовой политики компании. Он управляет новой технологией.

Представители последних поколений часто отдают предпочтение дистанционной работе. Но даже при наличии высшего образования в области бухгалтерского учета и управления финансами, эффективная и результативная работа возможна только после получения практического опыта, который так или иначе определяется временем, потраченным на обучение, саморазвитие и саму работу под наблюдением опытных бухгалтеров. Консервативные, но, как и раньше, действенные инструменты учебных практик включают следующие систематические действия:

- получение навыков у старших и более опытных сотрудников непосредственно в компаниях, работа помощником бухгалтера, познание всех тонкостей рабочих процессов (современная терминология называет этот процесс «наставничеством»);

- чтение соответствующей литературы, профильных журналов, сайтов и блогов;

- отслеживание изменений в законодательстве и проверка соответствия принятых практик ведения учета к новым требованиям;

- постоянное обучение на профильных курсах, семинарах и вебинарах.

Все указанные инструменты действенны не только для новичков, но и для более опытных специалистов. Самый ценный работник - это всегда тот, кто обладает профессиональной экспертизой. Курсы и вебинары, например, делают акцент на практике и дают рабочие инструменты, которые можно внедрять на предприятии сразу после обучения.

Таким образом, бухгалтерия в современном мире уже давно стала не просто умением правильно работать с цифрами. Теперь это - переплетение знаний из разных сфер деятельности (в том числе, юриспруденции и информационных технологий), опытный и дальновидный бухгалтер стремится усвоить это как можно быстрее.

\section{Библиографический список}

1. Баринов А.А., Запечников С.В. Методы и средства обеспечения конфиденциальности смарт-контрактов // Безопасность информационных технологий. - 2017. - № 2.- с. 16-23.

2. Баскин А.С. Уязвимая экономика. Стратегия перехода к устойчивому развитию [Текст] /А.С. Баскин // Вестник Удмуртского университета. - 2013. - № 2-3.- С. 5-20.

3. Венделева М.А. Информационные технологии в управлении.: Учебное пособие для бакалавров / М.А. Венделева, Ю.В. Вертакова.-Люберцы: Юрайт, 2016. - 462 с.

4. Гусейнова Д. И., Омарова Э.Ш. «ЕRP-СИСТЕМЫ В РОССИИ» - [Электронный ресурс]- Режим доступа. - URL: https://www.scienceforum.ru/2016/1802/26062

5. Кулиш Н.В., Семенова С.С. Информационные технологии: их роль и значение в бухгалтерском учете // NOVAINFO.RU, Toм: 3, № 58, 2017, C. 91-94

6. Короткова T. «Россия: объем рынка ЕRР-систем по итогам 2015 увеличился на 9\%» [Электронный ресурс] // URL: http://www.cnews.ru/news/line/2016-10-18_rossiya_obem_rynka_erpsistem_po_itogam_2015

7. Об информации, информационных технологиях и о защите информации. Федеральный закон от 27.07.2006 № $149-\Phi 3$

8. Ильина, О.П. Информационные технологии бухгалтерского учета: учебник для ВУЗов /О.П. Ильина.- М.: Юнити, 2011.- 300 с.

9. Практика управленческого учета: Опыт европейских компаний / Т. Аренс, У. Аск, А. Барретта и др.; Общ. Ред.: Т. Гроот и К. Лукка; Пер. с англ.: К. Юрашкевич и др.- Мн.: Новое знание, 2004.

10. Саломеева A. «ERP-системы: «за» и «против»» - [Электронный ресурс] - Режим доступа. - URL: http://www. pmprofy.ru/content/rus/247/2470-article.asp

11. Свон М. Блокчейн: Схема новой экономики // Москва: Издательство «Олимп-Бизнес». $-2017 .-240$ с. 
12. Слободняк И. А., Пискунов И.В. Актуальные проблемы автоматизации бухгалтерского учета / И.А. Слободняк, И.В. Пискунов // Бухгалтерский учет в бюджетных и некоммерческих организациях. - 2014. - № 7.- С. 29-34.

13. Сорокина Л.Н. Проблемы внедрения автоматизации учета и подготовки отчетности в условиях перехода на международную систему финансовой отчетности / Л.Н. Сорокина // Финансовая аналитика: проблемы и решения. - 2014.- № 3.-С. 13-17.

14. Шепелев А.В., Измайлов А.М. Теоретический анализ понятия конкурентоспособности организации на современном этапе развития экономики. Экономика и предпринимательство, № 12 (ч.4) (53-4), 2014 г. C.850-855.

15. http://www.sfx-tula.ru/news/infoblog/8971/ 